\title{
Epidemiologic Study of Female Sexual Dysfunction in Delta of Egypt
}

\author{
AHMED A. GAAFAR, M.Sc.; AHMED S. EL ABD, M.D.; HASSAN H. ELTATAWY, M.D. and \\ MOHAMMED A. GHALWASH, M.D.
}

The Department of Urology, Faculty of Medicine, Tanta University

\begin{abstract}
Background: Female sexual dysfunction (FSD) is characterised by disturbances in sexual desire and psychophysiological changes associated with the sexual response cycle. Female sexual dysfunction (FSD) is defined as disorders of libido, arousal, orgasm, and sexual pain that lead to personal distress or interpersonal difficulties. It is a common problem, affecting $30-78 \%$ of women.
\end{abstract}

Aim of Study: Was to report the epidemiologic aspects of female sexual dysfunction in Delta of Egypt.

Patients and Methods: This study was designed as a crosssectional one and conducted on married women attending urology and/or gynecology outpatient clinic in Delta of Egypt mainly Tanta University Hospitals; between April 2017 and October 2018. Counseling was performed to explain the goals, steps and security of information of the study with 2822 attending married women to outpatient clinics, 310 women refused to share in the. The response rate was $89 \%$. The number of included women in the study was 2512 .

Results: Based on the total sexual function score, 1455 (57.9\%) had sexual complaints (group A) while 1057 women $(42.1 \%)$ had no sexual disturbance (group B). The total score of FSFI ranged from 4.6 to 25.7 in group $A$ (mean=) and from 27.3 to 35.1 in group $\mathrm{B}(\mathrm{mean}=)$. $(p=0.001)$ Comparison of the individual domain scores showed that women in the sexual dysfunction group had significantly lower scores in all domains as compared to those without sexual dysfunction $(p=0.001)$.

Conclusion: Female sexual dysfunction is highly prevalent problem but underestimated due to cultural, religious factors, lack of awareness and information about sex.

Key Words: Female sexual dysfunction (FSD) - Female sexual function index (FSFI) - Ceserian section (CS).

\section{Introduction}

HEALTHY sexual relationship is a great important issue for human quality of life and general wellbeing [1]. Female sexual dysfunction (FSD) is a real worldwide health problem, its prevalence

Correspondence to: Dr. Ahmed A. Gaafar, E-Mail: ahmedabdelsattar 812@gmail.com ranged from $30 \%$ to $63 \%$ [2-4] . Many factors may affect female sexual function as age, socioeconomic factors, medical comorbidities, previous surgeries especially repeated vaginal deliveries, male sexual dysfunction, ..etc. [5]. It is believed that FSD is under-reported in Arab countries because of cultural and religious values, lack of sex education and embarrassment [6].

Epidemiological studies on FSD prevalence are of utmost importance in specifying the problem and treatment strategies. However, there is rarity in the literature regarding FSD in Arab and lowincome countries [7]. The aim of this series was to assess the prevalence and factors affecting FSD in women of the Delta of Egypt.

\section{Patients and Methods}

This study was designed as a cross-sectional one and conducted on married women attending urology and/or gynecology outpatient clinics in Delta of Egypt mainly Tanta university hospitals; between April 2017 and October 2018. Local ethical committee approval was obtained prior to starting patients' enrollment. Also, an informed consent was taken from all participants.

\section{Inclusion criteria:}

Neurologically intact, heterosexually active married women, aged >_20 years with marriage duration >-one year.

\section{Exclusion criteria:}

Pregnant women, those with pelvic disease, malignancy, pelvic radiation or complex psychic disorders were excluded from the study.

Complete history taking and thorough examination were done to detect any risk factors for female sexual dysfunction. Examination was performed in lithotomy position by a well-trained 
physician or nurse who measured the enteroital caliber and vaginal length. The need for any investigations was guided by the discretion of the physician.

A 19-item Arabic-translated questionnaire called Female Sexual Function Index (FSFI) was used to assess the sexual function of all participants during the last month including six domains; desire, arousal, lubrication, orgasm, satisfaction, and pain [8] The cut-off score used to indicate sexual dysfunction was $\leq 26.55$ [9]. A well-trained interviewer explained the details of the study and the questionnaire to each participant. The collected data was organized, tabulated and statistically analyzed by SPSS V22.

\section{Results}

A total of 2822 married women were initially evaluated for FSD, 310 women refused to share in the study. The response rate was $89 \%$. The number of included women in the study was 2512. Participants' ages ranged from 20 years to 60 years.

Based on the total sexual function score, 1455 (57.9\%) had sexual complaints (group A) while 1057 women $(42.1 \%)$ had no sexual disturbance (group B). The total score of FSFI ranged from 4.6 to 25.7 in group A (mean \pm SD is $14.15 \pm 5.14$ ) and from 27.3 to 35.1 in group B (mean \pm SD is $31.74 \pm 3.74)(p=0.001)$.

Comparison of the individual domain scores showed that women in the sexual dysfunction group had significantly lower scores in all domains as compared tothose without sexual dysfunction $(p=0.001)$. The lowest scores were noted in the lubrication, pain and satisfaction domains (Table 1).

In group A, about 935 patients (64.3\%) were complaining of more than one sexual domain. The remaining 520 patients $(35.7 \%)$ reported sexual dysfunction in one domain only, as follow 21 patients in domain No. 1,39 patients in 2 nd domain, 159 patients in $3 \mathrm{rd}$ domain, 75 in 4 th domain, 80 in 5 th domain and 145 participiants in 6 th domain. The highest prevalence was reported in lubrication and pain domains, while the lowest was in arousal and sex desire.

From multivariate logistic regression analysis of potential risk factors of FSD, it was found that aging, high education level, menopause, duration of marriage $>10$ years, hyperprolactinemia, urinary incontinence, pelvic organ prolapse, vaginal delivery, erectile dysfunction and premature ejaculation of the husband were associated with higher risk (Table 2).

Table (1): Domains of female sexual function index in both groups.

\begin{tabular}{|c|c|c|c|c|c|c|}
\hline \multirow{2}{*}{ Domains of FSFI } & \multicolumn{2}{|c|}{$\begin{array}{c}\text { Group A } \\
(\mathrm{N}=1455)\end{array}$} & \multicolumn{2}{|c|}{$\begin{array}{c}\text { Group B } \\
(\mathrm{N}=1057)\end{array}$} & \multirow{2}{*}{$t$-test } & \multirow{2}{*}{$p$-value } \\
\hline & Range & Mean \pm SD & Range & Mean \pm SD & & \\
\hline Desire & $1.2-4.8$ & $2.98 \pm 1.14$ & $4.8-6$ & $5.12 \pm 0.65$ & 54.892 & $0.001 *$ \\
\hline Arousal & $0.9-5.4$ & $3.12 \pm 1.35$ & $5.4-6$ & $8.71 \pm 0.32$ & 131.951 & $0.001 *$ \\
\hline Lubrication & $0.3-3.9$ & $1.84 \pm 0.98$ & $3.9-6$ & $4.78 \pm 1.12$ & 69.871 & $0.001 *$ \\
\hline Orgasm & $0.4-4.8$ & $2.41 \pm 1.05$ & $4.8-6$ & $5.18 \pm 0.71$ & 74.312 & $0.001 *$ \\
\hline Satisfaction & $0.8-3.6$ & $1.89 \pm 0.94$ & $3.6-6$ & $4.86 \pm 1.41$ & 63.291 & $0.001 *$ \\
\hline Pain & $0.4-4$ & $1.87 \pm 0.78$ & $4.4-6$ & $5.21 \pm 1.08$ & 90.012 & $0.001 *$ \\
\hline Total score & $4.6-25.7$ & $14.15 \pm 5.14$ & $27.3-35.1$ & $31.74 \pm 3.74$ & 94.552 & $0.001 *$ \\
\hline
\end{tabular}

Table (2): Multivariate logistic regression analysis of potential risk factors for female sexual dysfunction.

\begin{tabular}{llc}
\hline & OR (95\% CI) & $p$-value \\
\hline Age & $1.548(1.047-1.859)$ & $0.012^{*}$ \\
High education level & $2.665(1.126-3.509)$ & $0.024 *$ \\
Postmenopausal & $2.521(1.309-5.324)$ & $0.001 *$ \\
Duration of marriage >10 years & $3.457(2.451-7.532)$ & $0.001^{*}$ \\
Hyperprolactinemia & $12.452(3.526-27.854)$ & $0.001 *$ \\
Urinary incontinence & $2.352(1.249-6.531)$ & $0.010^{*}$ \\
Pelvic organ prolapse repair & $3.521(1.653-7.214)$ & $0.001 *$ \\
Vaginal delivery & $6.324(2.107-8.521)$ & $0.004 *$ \\
Erectile dysfunction & $0.235(0.054-0.745)$ & $0.001 *$ \\
Premature ejaculation & $5.324(4.174-9.521)$ & $0.001 *$ \\
\hline
\end{tabular}




\section{Discussion}

Sexual health is important factor for overall well-being couple health. That is why scientists have conducted extensive researches on the details of sexual function in both males and females. Worldwide, FSD is reported and characterized by continuous rising incidence. Moreover, FSD is more prevalent than that of the males [10]

In the current study, the prevalence of FSD was $57.9 \%$. This figure is higher than that reported by Ibrahim et al., [1] (52.8\%) who studied 508 Egyptian women from Suez governorate. On the other hand, it is lower than that of other 2 Egyptian researches performed in Dakahlia governorate of Lower Egypt (68.9\%) [4] and Sohag of Upper Egypt (76.9\%) [11]. As regard to the Middle East countries, FSD seems to be less prevalent; $46.2 \%$ in Iran [12], 48.9\% in Saudi Arabia [13] and $43.4 \%$ in Turkey. [14].

Different questionnaire has been used to assess FSD in the literature. Some studies did not use questionnaires or assessed some domains and neglected others especially lubrication and satisfaction. In this study, we chose the Arabic version of FSFI to assess all 6 domains $[4,8]$

Women with FSD in our study reported significantly low scores on all subscales of the FSFI compared with those without FSD, with the lowest score noticed in the lubrication and pain domains. Similar results were reported in Egypt [1], Saudi Arabia [13], USA [15] and Turkey [15]. Chedraui and colleagues [16] found that lubrication and pain are the most affected domains.

A significant association of FSD and older age was supported by several previous studies [1,14] It was probably due to the physiological processes of aging which effect on sexual function depends on several psychological, pharmacological and illness related factors. Another explanation is the increasing demands of growing children. In contrast to our finding, Fajewonyomi et al., [17] reported that women with younger age are at greater risk for FSD. Also, Ibrahim et al., [1] and Hassanin et al., [11] reported significantly higher prevalence of FSD amongst those who got married at young age $(<20$ years old $)$.

Moreover, postmenopausal women had a higher risk of FSD. Vaginal dryness and painful intercourse might explain this phenomenon. Also, FSD was found to be more prevalent among women suffering from urinary incontinence. Pelvic organ prolapsed repair was proved as another risk factor for FSD. This could be attributed to intraoperative injury to pelvic nerves or postoperative inflammation, fibrosis or mental disorders. Lou and Chen [18] found that both chronic pelvic pain and previous pelvic surgery were risk factors for FSD.

Also, Lou and Chen [18] showed that the prevalence was significantly greater among women who had undergone cesarean section compared to nulliparous women, but was significantly lower than that of vaginal delivery group. Injury to pelvic floor organization and nerves by pregnancy and childbirth might cause an increased incidence of sexual dysfunction. In the current report, FSD was significantly higher with vaginal delivery as compared to CS. Among the medical comorbidities of our participants, hyperprolactinamia was found to be a risk factor for FSD.

Regarding to the relationship between FSD and education level, it was found that FSD was significantly more common in college secondary school education level. It could be attributed to higher ability to express sexual dissatisfaction. Previous studies reported contradictory results as some authors agreed with our findings [1,13], while others reported that FSD was significantly higher in lower education levels $[\mathbf{1 9 , 2 0 ]}$ and explained this by their lack of psychosexual knowledge.

Tehrani and colleagues [21] reported higher FSD in recently married women and they believed that by time, women become more experienced in their sexual function and develop stronger emotional relationship with their partners. In contrast, this series showed increased prevalence of FSD in women married for $>10$ years. This could be assigned to their increasing age, lack of privacy in the presence of growing children and increasing awareness about their sexual dysfunction. Ibrahim et al., [1] and Hassanin et al., [11] reported similar results.

In the current study, the majority of women with FSD were more likely to have 2 or more children. This association was attributed to the anatomical changes caused by repeated deliveries, hormonal changes, lack of privacy for sexual encounters and increased family responsibilities $[\mathbf{1}, \mathbf{1 3}]$ El-Nashar et al., [4] reported that nulliparity is also a potential risk for FSD due to psychological and hormonal factors.

Expectedly, several researchers suggested that FSD was affected by male partner's sexual dysfunction and could be improved by its treatment 
[22]. In this study, an association was found between FSD and sexual dysfunction in their partners in group A as compared to those without FSD. This was in agreement with the findings of Ismail et al., [13] and Aslan et al., [14] . Premature ejaculation seemed to be the greatest factor influencing FSD followed by erectile dysfunction. Moreover; $34.5 \%$ of women claimed that their partners' sexual problem was the reason behind their sexual dysfunction. In contrast, Worly et al., [15] reported that women without sexual dysfunction were more likely to report male partner sexual problem. However this was the women impression and not an actual diagnosis.

Foreplay is an essential part of the sexual activity for both partners [23]. In our study, most women with arousal and lubrication disorders gave a history of deficient foreplay. This supports the findings of "The Global Better Sex Survey" which studied 12,563 male and female participants and revealed that foreplay was important to both partners [24]. Another study reported that inadequate foreplay was the main complaint of women with FSD [25] . Similarly, in an online survey of 2,920 females in the Middle East, reported that $60 \%$ of participants had inadequate foreplay that considered the cause of dysparaunia in $33.4 \%$. of them [25].

From multivariate logistic regression analysis for potential risk factors of FSD, it was increased with age, higher educational level, postmenopausal women, hyperprolactinemia, marriage duration $>10$ years, urinary incontinence, pelvic surgery as pelvic organ prolapse repair and vaginal delivery and male partner sexual dysfunction.

To the best of our knowledge, this was the largest cross sectional study that assesses FSD in Egypt and its results can help health professionals concerned with sexual health in Egyptian women.

\section{Conclusion:}

Despite the importance of FSD, it remains unclear as regards its prevalence and characteristics mostly because of shyness and lack of trained physicians. This study revealed high prevalence and outlined the specifications of FSD in the Delta of Egypt. We recommend direct assessment of female sexual function during gynecology and family planning visits. More studies from different geographical zones in Egypt are needed to consolidate our initial results focusing on patients' awareness and physicians' competency in FSD management.

\section{References}

1- IBRAHIM Z.M., AHMED M.R. and SAYED AHMED W.A.: Prevalence and risk factors for female sexual dysfunction among Egyptian women. Arch. Gynecol. Obstet. Jun., 287 (6): 1173-80, 2013.

2- AMIDU N., OWIREDU W., WOODE E., ADDAIMENSAH O., QUAYE L., ALHASSAN A. and TAGOE E.A.: Incidence of sexual dysfunction: A prospective survey in Ghanaian females. Reprod. Biol. Endocrinol., 8 (106): 1-6, 2010.

3- EL ATRASH G., ALI M.H., ABDELWAHAB H.A., ABDELREHEEM L.A. and SHAMAA M.: The assessment of sexual dysfunction in Egyptian women with lower urinary tract symptoms. Arab. J. Urol. Sep., 12 (3): 2348, 2014.

4- ELNASHAR A.M., EL-DIEN IBRAHIM M., ELDESOKY M.M., ALI O.M. and EL-SAYD MOHAMED HASSAN M.: Female sexual dysfunction in lower Egypt. BJOG., 114: 201-206, 2007.

5- American Psychiatric Association. Diagnostic and Statistical Manual of Mental Disorders. American Psychiatric Association (APA), 4 th Edn.Washington, p 537, 2000.

6- EL-ENEN M.A., RAGB M., EL GAMASYAEL N., ELASHRY O., EL-SHARABY M., ELBADAWY A. and FAYED N.: Sexual function among women with stress incontinence after using transobturator vaginal tape, and its correlation with patient's expectations. BJU. Int. Oct., 104 (8): 1118-23, 2009.

7- MOORE C.K.: Female sexual function and dysfunction Scott. Tenth Edition. In: McDougal W., Wein A.J., Kavoussi L.R., Novick A.C., Partin A.W., Peters C.A., et al., editors. Campbell-walsh urology, 6 Philadelphia: Elsevier: Saunders, p. 823-33, 2010.

8- ANIS T.H., GHEIT S.A., SAIED H.S. and AL KHERBASH S.A.: Arabic Translation of Female Sexual Function Index and Validation in an Egyptian Population. J. Sex. Med., 8: 3370-8, 2011

9- CARUSO S., INTELISANO G., LUPO L., et al.: Premenopausal women affected by sexual arousal disorder treated with sildenafil: A double-blind, cross-over, placebocontrolled study. BJOG., 108: 623-628, 2001.

10- MCCABE M.P., SHARLIP I.D., LEWIS R., ATALLA E., BALON R., FISHER A.D., et al.: Incidence and Prevalence of Sexual Dysfunction in Women and Men: A Consensus Statement from the Fourth International Consultation on Sexual Medicine 2015. J. Sex. Med., 13 (2): $144-52,2016$.

11- HASSANIN I.M., HELMY Y.A., FATHALLA M.M. and SHAHIM A.Y.: Prevalence and characteristics of female sexual dysfunction in a sample of women from Upper Egypt. Int. J. Gynaecol. Obstet., 108: 219-23, 2010.

12- JAAFARPOUR M., KHANI A., KHAJAVIKAN J. and SUHRABI Z.: Female sexual dysfunction: Prevalence and risk factors. J. Clin. Diagn. Res., 7: 287 780, 2013.

13- SMAIL S.A., SAYED D. S. and ABUSIKKIN I.A.: Prevalence and Risk Factors for Female Sexual Dysfunction in Saudi Women. Egyptian J. Dermatol. Androl., 32 (2): 53-66, 2012. 
14- ASLAN E., BEJI N.K., GUNGOR I., KADIOGLU A. and DIKENCIK B.K.: Prevalence and risk factors for low sexual function in women: A study of 1,009 women in an outpatient clinic of auniversity hospital in Istanbul. J. Sex. Med., 5: 2044-52, 2008

15-WORLY B., GOPAL M. and ARYA L.: Sexual dysfunction among women of low-income status in an urban setting. Int. J. Gynaecol. Obstet., 111: 241-4, 2010.

16- CHEDRAUI P., PEREZ-LOPEZ F.R., SAN MIGUEL G. and AVILA C.: Assessment of sexuality among middleaged women using the Female Sexual Function Index Climacteric, 12: 213-221, 2009.

17-FAJEWONYOMI B.A., ORJI E.O. and ADEYEMO A.O. Sexual dysfunction among female patients of reproductive age in a hospital setting in Nigeria. J. Health. Popul. Nutr. 25: 101-6, 2007.

18- LOU W.J., CHEN B., et al.: Prevalence and Factors Associated with Female Sexual Dysfunction in Beijing, China Chinese Medical Journal, June 20, Volume 130, Issue 12, 2017.

19- VAHDANINIA M., MONTAZERI A. and GOSHTASEBI A.: Help-seeking behaviors for female sexual dysfunction: A cross sectional study from Iran. BMC. Womens Health, 9: 3, 2009.

20- ABDO C.H.N., OLIVEIRA W.M.J.R., MOREIRA ED
J.R. and FITTIPALDI J.A.: Prevalence of sexual dysfunctions and correlated conditions in a sample of Brazilian women = results of the Brazilian study on sexual behavior (BSSB). Int. J. Impot. Res., 16: 160-6, 2004.

21- TEHRANI F., FARAHMAND M., SIMBAR M. and AFZALI H.: Factors Associated with Sexual Dysfunction; A Population Based Study in Iranian Reproductive Age Women. Arch. Iran. Med., 17 (10): 679-84, 2014.

22- SAND M.: Correlation between FSFI scores and sexual dysfunction in male partners in a random sample of registered nurses: The nurses' sexuality study, 9 th Congress of European Society for Sexual Medicine Book of Abstracts. J. Sex. Med., pp. 03-221:71, 2006.

23- SHAEER O., SHAEER K. and SHAEER E.: The Global Online Sexuality Survey (GOSS): Female Sexual Dysfunction among Internet Users in the reproductive Age Group in the Middle East. J. Sex. Med.,9: 411-24, 2012.

24- MULHALL J., KING R., GLINA S. and HVIDSTEN K. Importance of and satisfaction with sex among men and women worldwide: Results of the global better sex survey. J. Sex. Med., 5: 788- 95, 2008.

25- WITTING K., SANTTILA P., VARJONEN M., JERN P., JOHANSSON A., VON DER PAHLEN B., et al.: Female sexual dysfunction, sexual distress, and compatibility with partner. J. Sex. Med., 5: 2587-99, 2008.

\section{دراسة احصائية عن العجز الجنسى للنساء فى دلتا مصر}

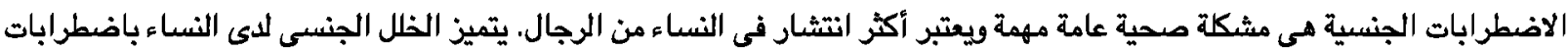

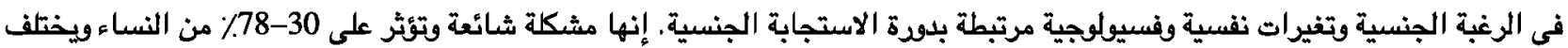

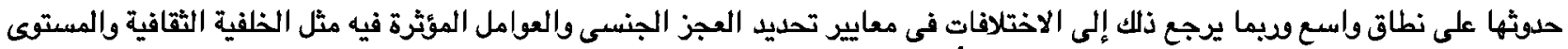

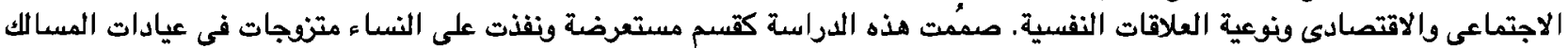

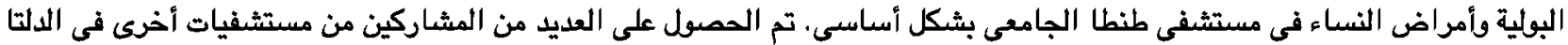

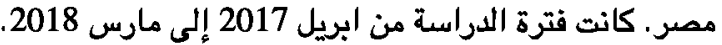

وقد أجريت الدراسة بعد موافقة من اللجنة الأخلاقية المحلية. وأيضا قدم جميع المشاركين موافقة مستتيرة مكتوبة قبل التسجيل في الدراسة.

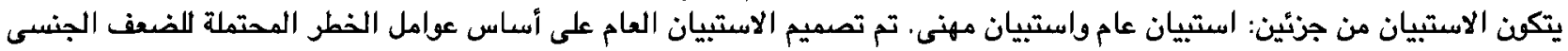

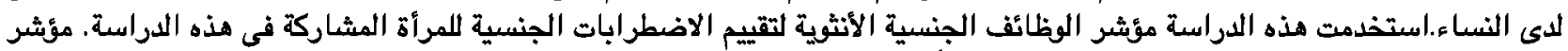

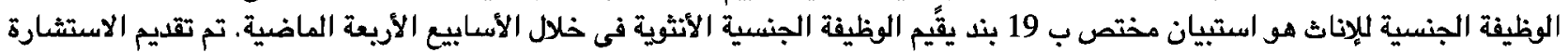

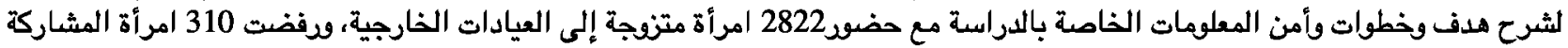

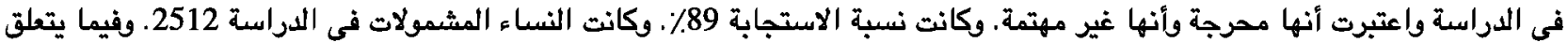

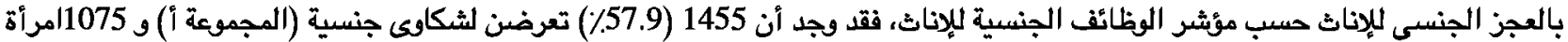

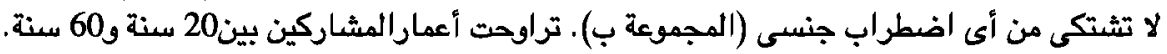

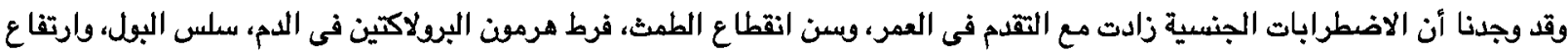

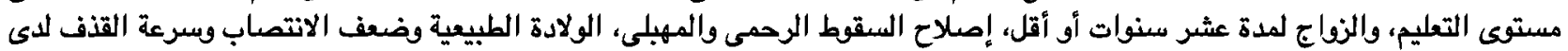

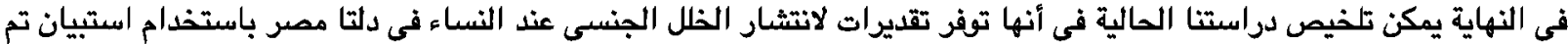

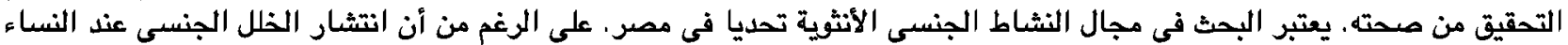

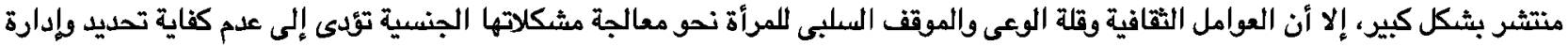

